\section{Linfadenitis por vacuna de bacilo Calmette-Guérin}

\section{Lymphadenitis due to Bacillus Calmette- Guerin vaccination}

\section{DEFINICIÓN}

La linfadenitis por vacunación con bacilo de Calmette-Guérin (BCG) es la complicación más frecuente de esta vacuna. Se define como el crecimiento de los ganglios linfáticos regionales ipsilaterales posteriores a la vacunación, su incidencia se estima en $<0.4 / 1000$ vacunados menores de 1 año y en 0.03/1 000 vacunados de entre 1 y 20 años de edad. ${ }^{1}$ Se recomienda que este término se utilice cuando el crecimiento ganglionar se palpe con facilidad, el paciente se mantenga afebril y en buen estado general. Se manifiesta con mucha frecuencia entre las 2 semanas y los 6 meses después de la aplicación de la vacuna y la gran mayoría ocurre en un lapso de 24 meses., ${ }^{2,3}$

\section{PRESENTACIÓN CLÍNICA}

Se han descrito dos formas de linfadenitis por BCG con distinta evolución natural: la forma más frecuente es la no supurativa, también Ilamada linfadenitis por bacilo de Calmette-Guérin. Comúnmente se alivia de manera espontánea en un periodo de pocas semanas sin dejar ninguna secuelas. Se caracteriza por:

- Antecedente de aplicación de vacuna con bacilo de Calmette-Guérin en el brazo ipsilateral al crecimiento ganglionar.

- El inicio es usualmente de dos a cuatro meses después de aplicar la vacuna BCG y en casi todos los casos ocurre en un lapso de 24 meses.

- Ausencia de fiebre o de otros síntomas constitucionales.

- Dolor ausente o mínimo sobre las lesiones.
Armando Reyes-Cadena

Médico adscrito a la Consulta Externa.

Instituto Nacional de Pediatría, Ciudad de México.
Recibido: 3 de febrero del 2015

Aceptado: 5 de febrero del 2015

Correspondencia: Dr. Armando Reyes Cadena Servicio de Consulta Externa de Pediatría Instituto Nacional de Pediatría cadenadr@yahoo.com.mx

Este artículo debe citarse como Reyes-Cadena A. Linfadenitis por vacuna de bacilo Calmette-Guérin. Acta Pediatr Mex 2015;36:122125. 
- El crecimiento ganglionar ipsilateral se presenta en más de $95 \%$ de los casos, los ganglios linfáticos cervicales se encuentran involucrados en $24 \%$ de los casos y los ganglios supraclaviculares en $18 \%$, ya sea de forma aislada o en asociación con crecimiento ganglionar axilar. En la mayoría de los casos hay sólo uno o dos ganglios linfáticos crecidos, aunque múltiples ganglios linfáticos también han sido reportados.

- Sólo uno o dos ganglios linfáticos están agrandados (palpables clínicamente) en la mayoría de los casos.

La linfadenitis supurativa puede desarrollarse en el lapso de 2 a 4 meses después de la vacunación. Ocurre en 30 a $80 \%$ de las linfadenitis por bacilo de Calmette-Guérin. Además de los datos previamente mencionados esta forma se caracteriza por edema y fluctuaciones en la piel que la cubre. Una vez que la supuración aparece el curso subsecuente consiste en descarga espontánea y formación de fístulas. La curación se lleva a cabo en el momento de la cicatrización y del cierre de las fístulas, proceso que habitualmente lleva varios meses y resulta frecuentemente en problemas estéticos. ${ }^{4}$

\section{FACTORES DE RIESGO}

- La mayoría de los casos ocurre por mala técnica en la aplicación de la vacuna (inyección subcutánea en vez de intradérmica). ${ }^{3-5}$

- Una sobredosis puede llevar a reacciones adversas más graves. La dosis recomendada es de $0.1 \mathrm{~mL}$, en caso de utilizar la cepa Pasteur y Danesa 1331, y de $0.05 \mathrm{~mL}$ en caso de usar la cepa Tokio. ${ }^{3-5}$

- Virulencia residual de la cepa bCG: Las cepas de bCG de diferentes manufacturas farmacéuticas tienen diferentes reactogenicidades. Las cepas más asociadas con linfadenitis han sido la Pasteur y Danesa $(4-13 \%) .^{3-5}$

- Viabilidad del producto final de la vacuna (las proporciones de bacilos vivos y muertos). La concentración de partículas vivas en las vacunas varía de 50000 a 3 millones por dosis de acuerdo con las cepas. Esto puede ser afectado por las condiciones de almacenamiento como la cadena de frío. ${ }^{3-5}$

\section{LINFADENITIS COMO DATO DE ALARMA}

La vacunación con bacilo de Calmette-Guérin es segura para los neonatos de término, con peso adecuado para edad gestacional y con un sistema inmunológico competente. Hoy en día el beneficio es claro en países donde la tuberculosis sigue siendo un problema de salud pública. Disminuye la incidencia de tuberculosis pulmonar (RR 0.74 IC 95\% 0.62-0.83), la muerte por tuberculosis (RR 0.35 IC 95\% 0.14-0.88) y la meningitis por Mycobacterium tuberculosis (OR 0.36 IC 95\% 0.17-0.70). ${ }^{6}$

La infección diseminada con bacilo de CalmetteGuérin ocurre en menos de 1 de cada 10000 neonatos vacunados y se asocia, principalmente, con defectos del sistema inmunitario como infección por el virus de la inmunodeficiencia humana, inmunodeficiencia combinada grave (SCID), enfermedad granulomatosa crónica (CGD) y defecto del eje interferón gamma-interleucina 12,23.7,8 Por esta asociación algunos autores recomiendan realizar abordaje diagnóstico de inmunodeficiencias primarias o secundarias en aquellos pacientes que presentan dichas complicaciones. Estos pueden cursar con complicaciones graves por la vacuna BCG como infecciones diseminadas que afectan piel, ganglios linfáticos, pulmón, hueso, sistema nervioso central y en algunas ocasiones Ilegan a ser letales. ${ }^{8}$

Por otro lado, 3 a $14.8 \%$ de los niños infectados con virus de inmunodeficiencia humana que 
son vacunados con BCG e inician tratamiento antirretroviral pueden desarrollar un cuadro conocido como síndrome inflamatorio de reconstitución inmunitaria por BCG (BCG-IRIS), en el que una infección latente por el bacilo de la vacuna se hace evidente una vez que el sistema inmunológico recupera su función. Lo más frecuente es que se presente como una BCGitis pero también se han descrito infecciones diseminadas y letales. ${ }^{9}$ La vacunación con bacilo de Calmette-Guérin está contraindicada en pacientes afectados por inmunodeficiencias primarias o infección por el virus de la inmunodeficiencia humana. ${ }^{8,9}$

\section{DIAGNÓSTICO}

El diagnóstico de linfadenitis por vacunación con bacilo de Calmette-Guérin es básicamente clínico. El paciente debe de tener una historia de vacunación reciente, crecimiento ganglionar axilar, supraclavicular o cervical ipsilateral al sitio de aplicación de la vacuna y sin otras causas identificables de adenitis; es suficiente para hacer el diagnóstico en la mayoría de los casos. La ausencia de fiebre, dolor y otros síntomas constitucionales permiten diferenciarla de la adenitis piogénica. ${ }^{4}$

\section{TRATAMIENTO}

El manejo de la BCGitis es controvertido y varía desde la simple observación hasta opciones médicas y quirúrgicas.

\section{Antibióticos}

Se han utilizado varios antibióticos (eritromicina) y fármacos antituberculosos (isoniacida y rifampicina). Estos medicamentos respaldan su eficacia en varias series de casos; sin embargo, ensayos clínicos controlados han mostrado que dichos fármacos no previenen la supuración ni acortan el tiempo de curación. La terapia con antibióticos estará indicada para el tratamiento de linfadenitis supurativa causada por sobreinfección con bacterias piógenas como Staphylococcus aureus o Streptococcus pyogenes. ${ }^{10,11}$

\section{Aspiración con aguja}

Algunos estudios han descrito que la aspiración con aguja puede prevenir la perforación espontánea y la formación de fístulas, acortar el tiempo de curación y proporcionar información diagnóstica de valor (i.e. coinfección con otras bacterias). Otros autores han sugerido la instilación de isoniacida durante la aspiración con aguja pero los beneficios de ese tratamiento aún deben confirmarse. ${ }^{4,10,11,12}$

\section{Escisión quirúrgica}

La escisión quirúrgica es una vía definitiva para remover los ganglios linfáticos afectados, promover una curación temprana y favorecer la recuperación de la herida. La escisión quirúrgica podrá considerarse en el caso de falla de aspiración con aguja, así como en aquellos pacientes con ganglios linfáticos multilobulados, en conglomerados, o bien en caso de adenomegalias mayores de $3 \mathrm{~cm} .{ }^{4,10}$

\section{Esperar y vigilar}

Para reacciones menores y linfadenopatía no fluctuante una conducta apropiada es la de "esperar y vigilar" con visitas de seguimiento. Durante las visitas se vigila que la reacción sea menor y que la linfadenopatía no desarrolle abscesos. $^{8}$

\section{REFERENCIAS}

1. Lotte A, Wasz-Hockert O, Poisson N, et al. Second IUATLD study on complications induced by intradermal BCGvaccination. Bull Int Union Tuberc Lung Dis 1988;63:47-59.

2. Goraya JS, Virdi VS. Bacille Calmette-Guérin lymphadenitis. Postgrad Med J 2002;78:327-329. 
Reyes-Cadena A. Linfadenitis por vacuna Calmette-Guérin

3. Greppi D, Guzmán M. Vacunas en tuberculosis. Archivos de Alergia e Inmunología Clínica 2007;38(4):148-154.

4. Chan WM, Kwan YW, Leung CW. Management of Bacillus Calmette-Guérin Lymphadenitis. HKJ Paediatr 2011;16:85-94.

5. Quezada, D.G, Meléndez M.A.G. Vacunas en tuberculosis. Archivos de Alergia e Inmunología Clínica 2007;38(4):148-154.

6. Colditz GA, Berkey CS, Mosteller F, et al. The efficacy of bacillus Calmette Guerinvaccination of newborns and infants in the prevention of tuberculosis: metaanalyses of the published literature. Pediatrics 1995;96:29-35.

7. Talbot EA, Perkins MD, Silva SF, et al. Disseminated bacilli Calmette-Guerin disease after vaccination: case report and review. Clin Infect Dis1997;24:1139-46.

8. Norouzi S, Aghamohammadi A, Mamishi S, Rosenzweig S, RezaeiN. Bacillus Calmette-Guérin (BCG) complications as- sociated with primary immunodeficiency diseases. Journal of Infection 2012;64:543-554.

9. James J. C. Nuttall and Brian S. Eley. BCG Vaccination in HIV-Infected Children. Tuberculosis Research and Treatment, Vol. 2011, Article ID 712736, 6 pages, 2011. doi:10.1155/2011/712736

10. Goraya JS, Virdi VS. Bacille Calmette-Guérin lymphadenitis. Postgrad Med J 2002;78:327-329.

11. Chan W.M., Kwan Y.W., Leung C.W. "Management of Bacillus Calmette-Guérin Lymphadenitis." HK J Paediatr 2011;16(2):85-94.

12. Abhulhamees F, Hummaida T. Surgical Management of BCG Vaccine-Induced Regional Lymph Nodes Adverse Effects. Annals of Pediatric Surgery 2009;5(3):187-193. 